\title{
THREE CASE REPORTS OF UTERINE ANOMALIES AND PREGNANCY
}

Sanjay Kumar C1, Deepthi H. R², Pradeep M. R², Lalitha Shivanna ${ }^{4}$

\section{HOW TO CITE THIS ARTICLE:}

Sanjay Kumar C, Deepthi H. R, Pradeep M. R, Lalitha Shivanna. "Three Case Reports of Uterine Anomalies and Pregnancy". Journal of Evolution of Medical and Dental Sciences 2014; Vol. 3, Issue 14, April 07;

Page: 3605-3608, DOI: $10.14260 /$ jemds/2014/2328

ABSTRACT: Incidence of uterine anomalies was 3.5-8\% of general population. Generally they are asymptomatic; a few may have gynecological symptoms and obstetric morbidities. If detected antenatally, close follow up is warranted till delivery to avoid obstetric morbidities. Surgical intervention in some of the anomalies will certainly help to improve birth rates significantly. We are presenting three different case reports of uterine anomalies detected accidentally during pregnancy and their outcome.

KEYWORDS: Uterus, Anomalies, Bicornuate, Pregnancy.

INTRODUCTION: Uterus develops by the fusion of two mullerian ducts at 6-12 weeks of intra uterine period. Septum present initially between the two mullerian ducts disappears later during the development and forms a single cavity. Disorders of lateral fusion of the mullerian ducts lead to uterine didelphys, septate $\&$ bicornuate uterus.

Incidence of uterine anomalies is around $3.5-8 \%$ in general population. ${ }^{1}$ Although some uterine anomalies cause infertility, most of them conceive without difficulty. Incidence of spontaneous abortion, cervical incompetence, PPROM, fetal loss, IUGR, preterm delivery, mal presentation, caesarean section, retained placenta and PPH are all increased when uterine malformation are present. ${ }^{2}$ By detection of these uterine malformations, we can correct them with recent operating modalities thereby preventing obstetric complications \& improving reproductive outcome.

We are presenting three different case reports of uterine anomalies detected accidentally during pregnancy which were admitted and operated at district hospital, Mandya institute of medical sciences, Mandya.

CASE 1: A 27yr old $\mathrm{G}_{3} \mathrm{P}_{1} \mathrm{~L}_{1} \mathrm{~A}_{1}$ with term gestation with breech presentation was admitted in labor. She had first vaginal delivery with birth weight of $2.5 \mathrm{~kg}$. Clinical examination showed incomplete breech presentation in labor. USG report showed Single live intra uterine gestation with incomplete breech presentation with right sided adnexal mass of $11 \times 8 \times 6 \mathrm{~cm}$.

Emergency caesarean section was done in view of fetal distress \& a live male baby of weight $2.75 \mathrm{~kg}$ was delivered. Per operatively bicornuate uterus with well-developed right horn of uterus was noticed (Figure 1A), tubes and ovaries were normal (Figure 1B). Post-operative period was uneventful and patient was discharged on $7^{\text {th }}$ post-operative day.

CASE 2: A primigravida with 36 weeks of gestation with cephalic presentation with PIH was admitted in labor with PROM. On examination her BP was 150/110 mmHg. P/A - uterus 34 weeks size \& cephalic presentation. $\mathrm{P} / \mathrm{V}-\mathrm{Cx}-30 \%$ effaced, os- $3 \mathrm{~cm}$ dilated with vertex at -2 stations. $\mathrm{P} / \mathrm{S}-\mathrm{vertical}$ 


\section{CASE REPORT}

septum was seen in the vagina about 2.5 " \& diagnosed as primigravida with border line preterm gestation with septate vagina in latent phase of labor. As her BP was persistently 150/100mmhg, Tab.

Labetalol $100 \mathrm{mg}$ was started \& patient was taken for emergency LSCS due to arrest of dilatation. Live male baby of weight $1.8 \mathrm{~kg}$ was extracted. Per-op findings showed septate uterus with complete septa from fundus to the vagina (Figure 2). Post- op period was uneventful \& discharged on 7th Post-operative day.

CASE 3: A patient with $\mathrm{G}_{3} \mathrm{~A}_{2}$ with 36.2 weeks of gestation with breech presentation with PIH and polyhydramnios, admitted with premature rupture of membranes. First two were spontaneous first trimester abortions. Investigation revealed normal PE profile and GTT. USG showed SLIUG of 37-38 wks. with breech presentation with BPP 10/10 and normal Doppler study.

LSCS done in view of fetal distress. Extracted an alive female baby of weight $2.92 \mathrm{~kg}$. Per-op finding showed septate uterus with partial septum (Figure 3). Post- op events were uneventful \& discharged on $7^{\text {th }}$ post-operative day.

DISCUSSION: Incidence of uterine anomalies is around 3.5-8\% in general population ${ }^{1}$. An insult at different levels of uterine development during intrauterine period leads to various uterine anomalies. Partial lack of fusion of two paramesonephric ducts produces a single cervix with varying degrees of separation in two uterine horns, leading to bicornuate uterus. It may be complete or incomplete depending on fundal indentation.

Obstetric complications depends upon the severity of fundal indentation. Incidence of bicornuate uterus is more common among uterine anomalies. Preterm deliveries, miscarriages and breech presentations were more common obstetric complications associated with bicornuate uterus, whereas incidence of infertility in bicornuate uterus is not different from general population. ${ }^{2}$

Majority of women with uterine malformations were asymptomatic. Dysmenorrhea \& dyspareunia are common among these population. ${ }^{3}$ Surgical reconstructions i.e. metroplasty for the bicornuate uterus can be considered for patients with recurrent miscarriages. Birth rate improves in this selected population from $2-21 \%$ to $60-80 \%{ }^{4}$

Partial lack of resorption of midline septum between two mullerian ducts leads to partial/ complete septate uterus. The defect is not a cause for infertility but is a common cause for recurrent miscarriages in second trimester. Resection of septum by hysteroscopy gives excellent results in improving birth rates. ${ }^{5,6}$ Fetal survival improves from $13 \%-91 \%$ after hysteroscopic metroplasty. ${ }^{7}$ Failure of development of one mullerian duct leads to non-communicating/ communicating rudimentary horn attached to unicornuate uterus (well developed mullerian duct).

Obstetric complications like spontaneous abortions, rudimentary horn pregnancy, IUGR and preterm labor are common with this anomaly. ${ }^{7}$ High number of ectopic pregnancies indicates removal of rudimentary horn and its tube when diagnosed. ${ }^{8}$

Failure of fusion of two mullerian ducts results in uterus didelphys. Obstetric complications like spontaneous miscarriage, malpresentation, IUGR and preterm labor are common.2,5 They are symptomatic if one side is obstructed. Early diagnosis of obstructed hemivagina and excision of vaginal septum will resolve the gynecological symptoms. Arcuate uterus has usually no adverse impact on complications of pregnancy. ${ }^{2}$ Investigations like transvaginal sonography, hysterosalpingography, sonosalpingography, hysteroscopy, MRI, and 3D ultra sound will reveal the uterine malformations. 
CONCLUSION: Uterine malformations are rare conditions, generally asymptomatic, may have gynecological symptoms \& obstetric morbidities. If detected antenatally should be counseled regarding complications. Follow up must be done closely till delivery. If there is repeated miscarriages surgical interventions can help in better outcome.

\section{REFERENCES:}

1. Chan YY, Jayaprakasan K, Zamora J, Thornton JG, Raine-Fenning N, Coomarasamy A. The prevalence of congenital uterine anomalies in unselected and high-risk populations: a systematic review. Hum Reprod Update, 2011; 17:761-771. 2.

2. Raga F, Bauset C, Remohi J, Bonilla-Musoles F, Simon C, Pellicer A. Reproductive impact of congenital müllerian anomalies. Hum Reprod 1997; 12:2277-2281.

3. Heinonen PK. Uterus didelphys: a report of 26 cases. Eur J Obstet Gynecol Reprod Biol.1984; 17: 345-50.

4. Maneschi F, Marana R, Muzii L, Mancuso S. Reproductive performance in women with bicornuate uterus. Acta Eur Fertil 1993; 24:117-120. 91.

5. Grimbizis GF, Camus M, Tarlatzis BC, Bontis JN, Devroey P, Clinical implications of uterine malformations and hysteroscopic treatment results, Hum reprod update 2001; 7: 161-74.

6. Fedele L, Biancgi S, Hysteroscopic metroplasty for septate uterus. Obstet Gynecol in North Am 1995; 22: 473-89.

7. Heinonen PK. Reproductive performance of women with uterine anomalies after abdominal or hysteroscopic metroplasty or no surgical treatment. J Am Assoc Gynecol laparoscopic 1997; 4: 311-17.

8. Heinonen PK. Unicornuate uterus and reproductive horn. Fertil steril 1997; 68: 224.

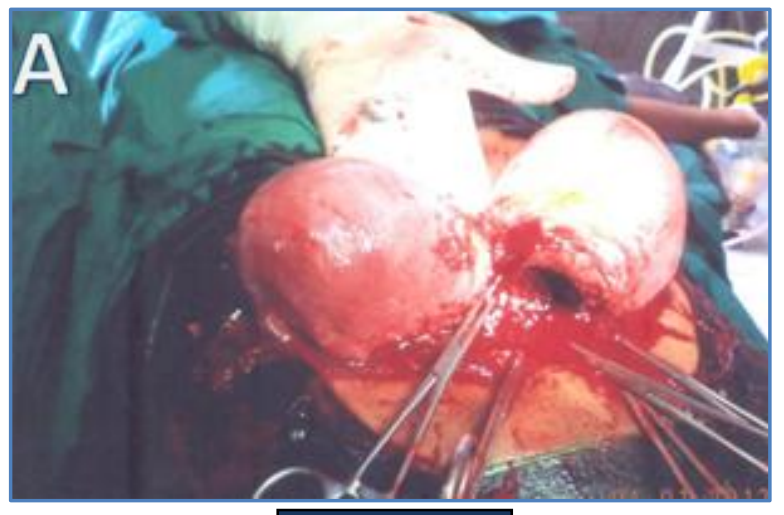

Figure 1 A

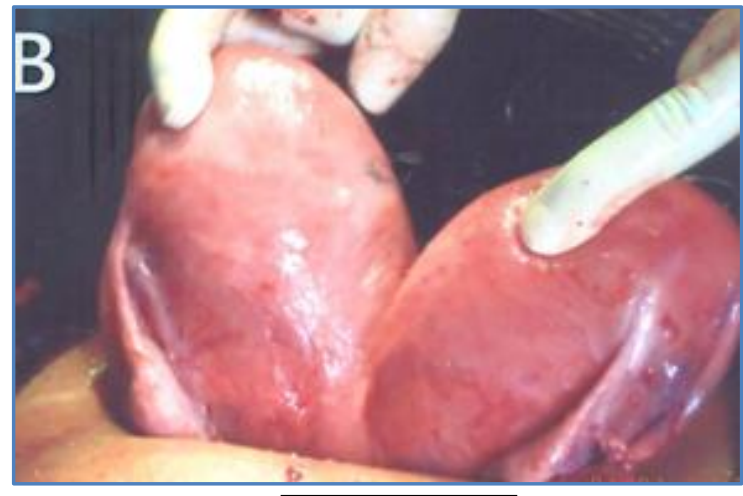

Figure 1 B

Figure 1: Case 1: A) Picture showing bicornuate uterus with well-developed right horn of the uterus. B) Picture showing posterior aspect of bicornuate uterus with normal tubes and ovaries. 


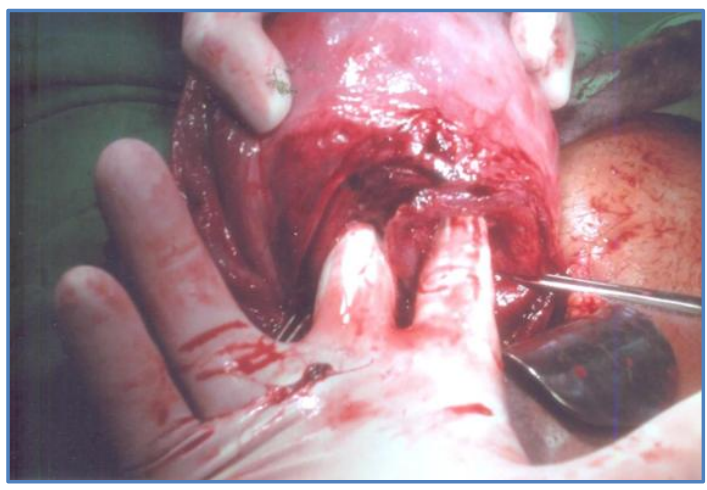

Figure 2

Figure 2: Case 2: Picture showing septate uterus with complete septa from fundus to the vagina.

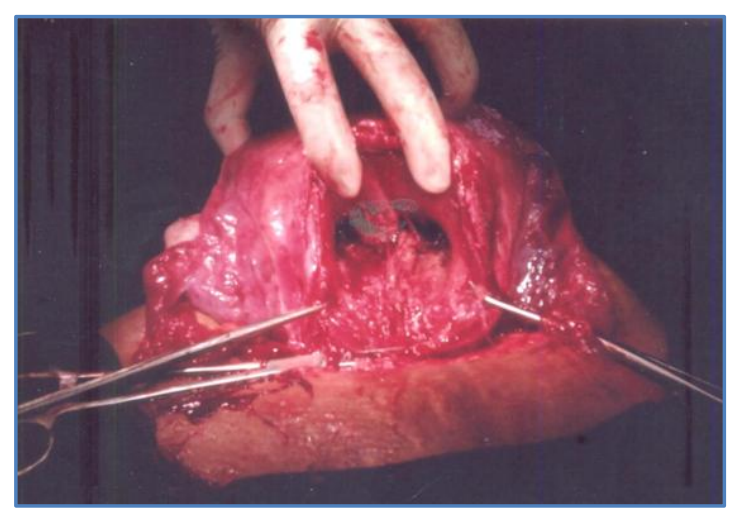

\section{Figure 3}

Figure 3: Case 3: Picture showing septate uterus with partial septum.

\section{AUTHORS:}

1. Sanjay Kumar C.

2. Deepthi H. R.

3. Pradeep M. R.

4. Lalitha Shivanna

\section{PARTICULARS OF CONTRIBUTORS:}

1. Assistant Professor, Department of Obstetrics and Gynaecology, Mandya Institute of Medical Sciences (MIMS), Mandya.

2. Junior Resident, Department of Obstetrics and Gynaecology, Mandya Institute of Medical Sciences (MIMS), Mandya.

3. Assistant Professor, Department of Obstetrics and Gynaecology, Mandya Institute of Medical Sciences (MIMS), Mandya
4. Professor, Department of Obstetrics and Gynaecology, Mandya Institute of Medical Sciences (MIMS), Mandya.

\section{NAME ADDRESS EMAIL ID OF THE CORRESPONDING AUTHOR:}

Dr. Lalitha Shivanna,

Professor,

Department of Obstetrics and Gynaecology, Mandya Institute of Medical Sciences (MIMS),

Mandya.

E-mail: drlalithashivanna@gmail.com

Date of Submission: 08/03/2014.

Date of Peer Review: 10/03/2014.

Date of Acceptance: 19/03/2014.

Date of Publishing: 01/04/2014. 